\title{
AUTOMATIC COMPUTING MACHINERY
}

Edited by the Staff of the National Applied Mathematics Laboratory of the National Bureau of Standards. Correspondence regarding the Section should be directed to Dr. E. W. Cannon, 415 South Building, National Bureau of Standards, Washington 25, D. C.

Technical Developments

\section{A Punched Card Machine Especially Equipped for Scientific Computations}

The author believes that a description of the punched-card machine now in use at the Norwegian Defence Research Establishment might be of some general interest.

The nucleus of the installation is a type $\mathrm{C} 3$ multiplying punched-card machine, purchased from the French Compagnie des Machines Bull. The original plugboard supplied at the time of purchase has been replaced by another almost double the size, and, by making certain other additions, the range of usefulness of the machine has been extended to include many types of calculations which are not normally practicable with punched-card machines.

The machine has 96 counting wheels, which are connected in groups of three by carry-over. Connection of the groups is determined by the plugging of the carry-over. Four 3-digit counters may be used for a multiplier and four others for a multiplicand, thus allowing two 12-digit numbers to be multiplied. The product is formed by the usual left and right hand principle, the two partial products being finally added together. It will be seen that even when two 12-digit numbers are multiplied, there are eight 3-digit counters which are not used. Although the counters do not permit subtractions to be performed directly, a number may be subtracted by adding its nines complement, and using "end-around" carry.

The operations of multiplication, addition, subtraction, conversion of a number into its nines complement and clearing may be performed. In any cycle only one type of operation can be performed. In order to transfer a number from one counter group to another, 48 change-over relays are provided, each relay having three sets of contacts.

A programme is limited by the 44 cycles which are built into the machine. However, the cycles may be connected in any desired sequence and used over and over again. With each cycle is associated a total of 4 "command" hubs, which are connected to the positive side of the 48-volt supply during the time the cycle is in progress. The operation to be performed during a cycle is determined by plugging from the hubs, the change-over relays being energized in the same way.

It is of interest that a multiplication must be completely programmed, one cycle for each digit in the multiplier and one for the addition of the partial products. Two command hubs are used for each digit, one determining the digit selected from the multiplier and the other determining the amount of left shift of the partial product. Furthermore, any digit or digits 
of the multiplicand may be suppressed during multiplication with any digit of the multiplier. This feature permits several trick-pluggings, e.g., several products may be formed at the same time, and it may even be possible to obtain the sum of several products in one operation.

In the event that more than one multiplication occurs during a problem, a uniselector is provided. The uniselector is stepped during each multiplication, usually in the cycle where the partial products are added. The impulse which starts the cycle following a multiplication is led to the input of the uniselector, and the cycle which is required to follow the multiplication is then initiated from the output hubs of the uniselector. These hubs, 50 in number, may be used for a variety of other purposes as well.

Eight sign-control units have been connected to eight experimentally selected counting wheels, those which experience in use of the machine have appeared to be most useful for this purpose. Each unit has a changeover relay, six relays having two sets of contacts, and the remaining two having three sets of contacts. The sign control takes up one position if the associated counting wheel indicates a nine and assumes the alternative position when any other number is indicated.

By means of a comparison unit, provision is made for comparison at the upper and lower brushes of two 6-digit numbers from two consecutive cards. Mention must also be made of ten relay units which can remember a pulse. Six of these units are cleared at the beginning of a card cycle, and the other four by impulses sent to the clearing hubs either by $x$ punches or in any cycle by pulses from the command hubs. In addition, there have been installed eight units similar to the first six, except that they clear in the card cycle when the zeros are passing the brushes. If these units are set up from the lower brushes they work exactly as the other six, but by setting them up from the upper brushes other obvious effects are obtained. The outputs from the units consist of a positive voltage on an output hub which is normally connected to the bobbin of one of the change-over relays. The sign-control relays, and the relays controlled by memory units, may be used to switch the succession of cycles. Thus, although the machine is not directly designed for division, this operation can easily be programmed.

Numbers may be extracted from the machine in three different ways. They can be punched into the cards supplied to the machine, or into new cards passing through an auxiliary punch, or they can be recorded by teleprinter. In the first instance the machine must stop, but this may be avoided in the other two cases by inserting a 24-digit relay-storage unit.

In order to check the complicated plugging required in some problems, a panel with 300 indicator lamps, to show the state of all important relays, has been added. A special feature permits the running of single cycles, allowing observation of the behaviour of the machine during this period.

Further technical details are likely to be of interest only to those actually using the equipment, and the author presents now an outline of some problems solved.

(a) Calculation of primes. This problem was attempted only as a demonstration test. The method of successive division was used. Observation was made after each division to see if the remainder was zero or not. Division in each case was performed by subtracting the divisor, 10 times the divisor, 100 times the divisor, etc., until the dividend became negative; division 
proper was then started from this point. In this way a minimum number of cycles was used. The machine ran continuously for 30 hours, and produced the primes up to 3600 on the teleprinter output. A single punched card was used, giving 7 as the first number to be tested.

(b) Calculation of ballistic curves. The ballistic curves for a slow rocket projectile were obtained from

$$
\begin{aligned}
\dot{\xi} & =-k v \xi \\
\dot{\eta} & =-k v \eta-g \\
\dot{x} & =\xi \\
\dot{y} & =\eta \\
v^{2} & =\xi^{2}+\eta^{2} .
\end{aligned}
$$

In the case considered $k v=a+b\left(\xi^{2}+\eta^{2}\right)$ and the simple integration formula

could be used.

$$
\xi_{1}=\xi_{-1}+2 h \dot{\xi}_{0}
$$

The initial values of the first two instants and the time of flight were punched into two cards for each curve. The values of $t, \xi, \eta, x$ and $y$ at second intervals during the total time of flight of 20 seconds were given in tabular form by the teleprinter. Eighty curves were computed in a little over six hours.

(c) Solution of linear equations. The solution was obtained by Verzuh's method, (see $M T A C$, v. 3, p. 453-462), but, because of the extra facilities available, the process was considerably simplified.

The first equation was divided by its leading coefficient, and two cards were punched by, the auxiliary punch for each coefficient. By means of a sorter these cards were then mixed with the cards of the other equations, and one card was punched for each of the coefficients in the resulting equations, where one unknown was eliminated. The reason for computing two cards in the first case was that, whilst one set of cards was used by the machine for eliminating an unknown from one equation, the other set could be mixed with the cards giving the next unknown. Normally several equations are solved simultaneously. Whenever the machine has finished the calculations for one equation, the teleprinter prints the sum of the cards just punched. As there is an auxiliary card for each equation, containing minus the sum of all the other coefficients in the equation, the teleprinter would always print 0 or -1 if no round-off errors existed. Each equation was preceded by an $\mathrm{X}$-punched master card, different for the first equation and the other equations. This card not only caused the teleprinter to print the contents of the counter giving the sum of the previously punched cards, but also cleared this counter and switched the machine to the correct programme. No manual switching was therefore required. Ten sets of four equations with four unknowns were solved in two hours by this method.

The author believes that it would not be worth while to construct a more flexible electromechanical computor than the one described, because of the inherent slow speed of such punched-card machines. The introduction of electronic techniques into the conventional punched-card system is a stage which will probably be superseded very soon by the use of a true all-purpose electronic computor. Such a machine may, if so desired, have punched cards 
as input and output media. For this reason the author has not incorporated an electronic multiplier in the machine described. The cost of the equipment is about 20,000 dollars, and it is already possible to buy an electronic generalpurpose computor for about this price. It would seem therefore that the era in which punched-card machines have been applied to scientific computations will very soon be past.

Norwegian Defence

JAN V. Garwick

Research Establishment

Kjeller, Norway

\section{Bibliography of Coding Procedure}

The material described below is among that which has been added to the collection at the National Bureau of Standards Computation Laboratory. A similar collection is available at the Numerical Analysis Research, Univ. of California, Los Angeles 24.

Material for inclusion in these collections should be sent to the Computation Laboratory, National Bureau of Standards, Washington 25, D. C., for the attention of J. H. WeGsTEIN.

56. J. W. Backus, "The IBM 701 Speedcoding system," Assoc. Computing Machinery, Jn., v. 1, 1954, p. 4-6. (Cf. item 58 of this Bibliography.)

57. H. H. Goldstine, "Some experience in coding and programming with the Institute Computer," Argonne National Laboratory, Proceedings of a symposium on large scale digital computing machines, August 3-5, 1953, ANL Report 5181, p. 273-278.

It is pointed out that it is not possible, with present day equipment, to divorce the engineering and mathematical difficulties in program preparation. Limitations on read-around ratio imply restrictions on coding; on the other hand, mathematically redundant checks are useful both in code checking and problem running.

A code-checking scheme recommended is first the checking of the arithmetics of the code (e.g. sub-routines purporting to represent a function accurately or approximately) and then the logics of the code. In the first step a specialization of parameters is often helpful (too great specialization must be avoided-cf. R. A. BRooker, S. GILl, D. J. WHEELER, $M T A C$, v. 6, p. 112-113). In the second stage it is useful to record the path of the control through the sub-routine complex. Fast printout of the full memory, to be contemplated at leisure, away from the console, has proved advantageous.

The importance of keeping an adequate diary describing the day-today development of the solution of a problem is stressed.

It is interesting to note that it has been decided to add hardware to the machine to detect overflows or spills.

NBSCL

J. T.

58. International Business Machines CoRP., Bibliography on the Use of IBM Machines in Science, Statistics, and Education. New York, January 1954.

59. W. L. VAN DER POEL, "Dead programmes for a magnetic drum automatic computer," Applied Sci. Research, v. 3B, 1953, p. 190-198. 
Dead programming here refers to programs stored in permanent memory and this paper points out the value of such programming.

60. C. Ross, C. S. Fluke, H. S. Toney, Handbook for OA RA C Programming and Coding. Wright Air Development Center, Nov. 1952.

This is a concise set of notes for guidance and reference in programming for the OARAC. It includes the order code, a glossary of terms, and examples of simple codes.

61. Programming Univac fac-tronic Systems. Instruction Manual I. Remington Rand Inc., Philadelphia, 1953, 249 pages.

The Remington Rand Organization is to be thanked for, as well as congratulated upon, the first volume of its Instruction Manual (it is, however, bulky and expensive). It not only provides an excellent means for learning to code on the UNIVAC, but also contains enough information of a general nature to benefit all devotees of high-speed computation. The text is exposed clearly enough so that a veritable tyro in the coding field can learn its principles solely from a perusal of this book without any other aid.

The first eight chapters, which contain the essential information about coding on the UNIVAC, can be mastered in about two weeks by a beginner. Chapter 9, which gives an elementary description of the engineering principles involved in the operation of a high-speed computer, will prove quite interesting for many readers, although it is not essential for the acquisition of coding skill. This reviewer is tempted to make the same statement anent Chapter 10, dealing with the Flow Chart (since she has never found it necessary to use one), but it is sure to arouse the ire of the numerous advocates of this supposed aid in programming.

The last Chapter serves as an Appendix and will be found most useful by the coder, especially as it lists all of the codes in alphabetical order along with complete explanations, whereas in the previous chapters they were given in small sets only and grouped according to operation. The textbook is further enhanced by the inclusion of many exercises in each chapter and of several excellent charts-some bound into the volume, others placed loose within a pocket on the inner back cover.

The beginner will regret the absence of answers to the exercises with which he might compare the results of his first timid attempts at coding. He will welcome, however, the second volume dealing with advanced techniques in programming and coding, promised by the publisher. This reviewer would welcome even more a detailed operators' manual, so that an advanced programmer could learn to use the machine without having to rely on the services of another person.

A word of advice to a newly established laboratory planning to make this manual its sole textbook: One cannot expect a manufacturer to highlight those peculiarities of his machine which for the unwary user become costly and irritable pitfalls-although the UNIVAC is far less vulnerable on this score than are most of the other computers. It is imperative, therefore, to append another chapter to the manual, expounding the danger points and means for avoiding trouble. One illustration should suffice. The UNIVAC command for shifting to the right is 
a negative number-a fact which must be borne firmly in mind when attempting to modify this command.

\section{NBS}

I. RHODES

62. BETz, B. K., An ORDVAC Floating Binary System. Ballistic Research Laboratories, Aberdeen Proving Ground.

Memorandum Report No. 733.

63. Naval Proving Ground, Dahlgren, Va. Routines for the MARK III Electronic Calculator.

64. Massachusetts Institute of Technology. Mechanical Translation. Devoted to the Translation of Languages with the Aid of Machines. Vol. 1, No. 1, March 1954.

The editors of this publication plan to publish it only occasionally and at irregular intervals in 1954. The first issue is devoted primarily to a bibliography of existing literature on the subject.

65. Roy Goldfinger, Nerw York University Compiler System. New York University, A.E.C. Computing Facility. Feb. 10, 1954.

66. Digital Computer Laboratory, University of Illinois. ILLIAC Programming, A Guide to the Preparation of Problems for Solution by the University of Illinois Digital Computer.

The ILLIAC is available for use by personnel of the University of Illinois provided users code their own problems. This manual is designed to teach how to code for the ILLIAC and how to make use of all its facilities. It includes chapters on: the arithmetic of the ILLIAC, the order code, subroutines and interpretive routines, the decimal order input, scaling, machine methods and coding tricks, checking methods, tape preparation, calculation of running time, preparation of a complete program, the cathode ray tube display, the program library, and definition of terms.

This, like the UNIVAC Instruction Manual and WHIRLWIND Comprehensive System Manual, is a good example of a text for a course in machine programming or a manual for self taught users of a specific electronic digital computer.

NBSCL

J. WeGstein

67. Digital Computer Laboratory, Massachusetts Institute of Technology. WHIRLWIND Memoranda M-2527, M-2539.

The WHIRLWIND, operating in a supervisory mode, is used to simulate different easy-to-use digital computers. One of these pseudocomputers is called the "CS Computer" (Comprehensive System) and another is called the "Summer Session Computer." These memoranda include manuals which are suitable as texts for a course in programming for the respective computers. These memoranda also provide a description of other features of the very interesting experiments in systems of high speed computation being conducted at M.I.T. 


\section{BiBLIOGRAPHY Z}

1133. Anon., "New digital computers developed," Aviation Week, April 12, 1954 , p. $60-63$.

A brief account of the new Bendix Computer and ElectroData Corp.'s Model 203 (ElectroData Corp.-a subsidiary of Consolidated Engineering Corp.).

The Bendix Computer is a digital differential analyzer, operating in a decimal numbers system. It can be used to solve linear and non-linear differential equations or simultaneous sets of such equations, or for integral equations, split-boundary value problems, and individual or simultaneous sets of linear or nonlinear algebraic and transcendental equations. The machine can be programmed from punched tape or a manual control panel; output is recorded on punch tape.

The Model 203 is a high speed general purpose computer, operating serial fashion in binary coded decimal number system. It includes a magnetic drum as well as an accessory magnetic tape storage unit. Its input may be from standard punch-card equipment or from a specially designed photoelectric reader operating from previously punched tape. Output can be recorded on standard punch cards, tape, or be tabulated on an electric typewriter.

Both computers as described by their manufacturers are in the medium price range.

NBSCL

A. R. Cock

1134. Anon., "These machines think," Signal, Nov.-Dec. 1953, p. 14-16.

This article describes the first calculator of comparable capacity to be produced in quantity-the IBM Data Processing Machine, the 701 which rents for $\$ 11,900$ a month, or more, depending on storage capacity.

Its memory devices consist of cathode ray tubes, magnetic drums and magnetic tapes. It is capable of performing more than 16,000 addition or subtraction operations a second and more than 2000 multiplication or division operations a second. The magnetic Drum Storage Units will store more than 80,000 digits and the Magnetic Tapes have a capacity of more than $2,000,000$ digits a tape. Results can be printed by means of a 150 line-aminute printer at the rate of 1050 ten-digit numbers a minute or punched on cards at the rate of 2400 ten-digit numbers a minute or stored on magnetic tapes at the rate of 1200 ten-digit numbers a second.

NBSCL

R. K. ANDERSON

1135. B. V. BowDEN, ed., Faster than thought, a symposium on digital computing machines. London, Pitman and Sons, Ltd., 1953, 414 p. Price 35 shillings.

Faster than thought is an interesting account of the development and application of electronic digital computing machines in England. In this symposium, Dr. BowDEN has edited the contributions of twenty-four British experts, including himself, to produce an entertaining and satisfying description of the genesis of modern digital computing machines, their theory 
and design and their multi-faceted applications in industry, commerce and scientific research.

Beginning with a foreword by the Earl of HALSBURy, managing director of the National Research Development Corporation and a preface by the editor, the book is divided into three main parts: Part One, The History and Theory of Computing Machines; Part Two, Electronic Computing Machines in Britain and America; Part Three, Applications of Electronic Computing Machines. Included also are a brief index, glossary and two appendices, one a reprint of pages 666-731 of TAYLOR's Scientific Memoirs, v. III, including editorial notes by the translator, the Countess of LOvELACE, the other extracts from four letters from the Lovelace Papers.

Some indication of the balance and flavour of the book can be gleaned from the enumeration of the contents of its twenty-six chapters, five of which are included in Part One, nine in Part Two and the remaining twelve in Part Three. Part One includes the following: A Brief History of Computation, The Circuit Components of Digital Computers, The Organization of a Typical Machine, The Construction, Performance and Maintenance of Digital Computers, Programming for High-speed Digital Calculating Machines. Part Two treats the University of Manchester Computing Machine, calculating machine development at Cambridge, automatic computation at the National Physical Laboratory, the Harwell electronic digital computer, the Telecommunications Research Establishment parallel electronic digital computer, the Imperial College Computing engine, the Royal Aircraft Establishment sequence-controlled calculator, calculating machines at the Birbeck College Computation Laboratory and six pages on computers in America. In Part Three, special-purpose automatic computers are defined and there are discussed, in separate chapters, applications of electronic computing machines in logical problems, crystallography, meterology, ballistics engineering, government calculations, business and commerce, economics, dynamical astronomy, the playing of games-nim, draughts and chess. Finally, in the closing chapter there is a stimulatingly temperate comparison of thought and machine processes.

With respect to Faster than thought, the reviewer is inclined to agree with the statement in the foreword that "It is undoubtedly the best general account yet written." It contains much material which will interest both specialists in the development of electronic computing machinery and potential users of this amazing equipment. Its account of the work of ChARLES BABbage a hundred years ago, the interest of Lady Lovelace in his attempts to build large-scale automatic digital machinery and her pioneering work in programming, the competent discussion of computer applications ranging from playing chess or draughts to payroll computations and scientific calculations - all these are among many features of the book which will make it stimulating reading for the general reader and specialist alike.

Accomplishment in the electronic digital computer field has reached a magnitude which makes it impracticable to achieve completeness in a reasonable length exposition on the subject. It nevertheless is difficult to understand the omission of mention of the epoch-making large-scale Bell Telephone Laboratories' Relay Computers and the parallel-mode, electro- 
static-store National Bureau of Standards Western Automatic Computer in Faster than thought. Again brief mention could have been made of the versatile E. U. ConDoN's relay machine to play the game of nim demonstrated about two decades ago at the New York City World's Fair, evoking considerable interest there. Finally, some indication of the trend of activity concerning electromagnetic and electronic digital computers on the Continent, including the development of computers and their application, would not have been unwelcome. In the evaluation of the book as a whole, these points appear of minor consequence and Dr. BowDEN is to be congratulated upon his contribution to the literature on modern electronic digital computers.

E. W. C.

1136. D. T. Caminer, L. Fantl, G. S. D. King, T. R. Thompson, \& W. B. WRIGHT, "The use of a high speed automatic calculator in the refinement stages of crystal-structure determinations," Acta Crystallographica, v. 7, Part 3, 1954.

Refinement can be said to begin when approximate atomic positions have been found, and the phases of the most important structure factors are known. Best-known methods available for refinement are 1. The Fourier Method, 2. The Differential Fourier Method, 3. The $\left(F_{0}-F_{c}\right)$ Fourier Method and 4. The Method of Steepest Descent and Least Squares. For automatic calculation, the authors found method (2) most appropriate for the first stages of the refinement of coordinates and method (4) for the final stages. The Quarichi (1949) modification of (4) was used.

The calculator used was the LEO, a machine built for the Lyons Electronic Office. LEO is a serial, single-address, binary machine. It has a store of sixty-four mercury delay lines, providing a capacity of 2048 words of 17 binary digits. It has paper-tape input, photoelectrically read.

Programs were worked out for nicotinamide, which has the space group $p 2_{1} / a$. The computational procedure could be readily modified for other centrosymmetric space groups. Application to acentric space groups would be more complicated.

Flow diagrams are given for the two programs of computation. An analysis is made of storage space required and the time needed for the calculations.

E. W. C.

1137. W. C. Carter \& M. Ellis, "A comparison of order structures for automatic digital computers," Operations Research Soc. of Amer. Jn., v. 2 , no. 1,1954 , p. $41-58$.

A method is outlined whereby order structures of the 1-, 2-, 3-, and 4-address types may be analyzed for application in a particular type of computation. The purpose is to assist in determining which will provide the greatest speed of operation and the greatest efficiency of storage in a proposed machine design. The method is applied to a payroll calculation, and the resultant computation times, on comparable machines with singleaddress and 3-address order structures, are presented. Some details of the 
different types of orders assumed to be used with the two different order structures are given.

NBSEC

R. A. KIRSCH

1138. M. J. Mendelson, "The decimal digital differential analyzer," Aeronautical Engineering Review, v. 13, 1954, p. 42-54.

This is a very clear and simple introduction to the logic of the digital differential analyzer. It explains the algorithm for numerical integration, the method of representing negative numbers and zero or negative rates, the organization of digital integrator registers on a magnetic drum, some examples of interconnections to solve simple differential equations, the rules governing scaling of magnitudes, and some special techniques. The latter include the decision integrator, the signum function, constant multipliers, multiplication, and division.

NBSEC

R. D. Elbourn

\section{News}

The five hundred and second meeting of the American Mathematical Society was held at the University of Chicago on Thursday, Friday, and Saturday, April 29, 30 and May $1,1954$.

The program included a symposium in Applied Mathematics (sponsored by the Society and the Office of Ordnance Research) of which the following papers are relevant here.

Session II W. W. LeUTERT, Ballistic Research Laboratories, Chairman.

Computational methods, M. R. Hestenes, University of California, Los Angeles

Motivations for working in numerical analysis, JoHN ToDD, National Bureau of Standards

Some numerical computations in ordnance problems, A. A. BenNetr, Brown University

Western Computer Conference and Exhibit. The Western Computer Conference on "Trends in Computers: Automatic Control and Data Processing" was held at the Ambassador Hotel in Los Angeles, California, February 11-12, 1954, under the joint sponsorship of the American Institute of Electrical Engineers, the Institute of Radio Engineers and the Association for Computing Machinery.

Opening Ceremonies-Thursday, February 11, 10:30 AM

Welcome Address

D. H. Lehmer, Professor of Mathematics, University of California, Berkeley

Keynote Address

W. W. McDowelL, Director of Engineering, International Business Machines Corp., Endicott, N. Y.

Session I-Thursday, February 11, 2:00 PM

Automatic Control-Systems

John M. Salzer, Hughes Research and Development Laboratories, Culver City, California, Chairman

An Experimental Digital Flight Control System

Maier Margolis, J. B. Rea Company, Inc. and ERIC WeIss, Dynalysis, Inc.

The DIGITAC Airborne Control System

E. E. Bolles, D. W. Burbeck, W. E. Frady, E. M. Grabbe, Hughes Research and Development Laboratories 
Application of Operational Digital Techniques to Industrial Control

Digital-Analog Machine Tool Control System

Experiments with a Digital Computer in a Simple Control System
Bernard M. Gordon, Laboratory for Electronics, Inc.

Harry W. Mergler, Lewis Flight Propulsion Laboratory of the National Advisory Committee for Aeronautics, Cleveland, Ohio

T. J. Burns, J. D. Cloud, J. M. Salzer, Hughes Research and Development Laboratories

Session II-Thursday, February 11, 2:00 PM

Data Processing-Systems

The Automatic Handling of Business Data

Business Data Processing:

A Case Study

A. The Retailer's Unit Control Problem

B. Unit Control Systems Engineering

C. A Solution for Automatic Unit Control

D. The System in Operation

Session III-Friday, February 12, 2:00 PM

Automatic Control-Equipment

Approaches to Design Problems in Conversion Equipment

A Multi-Channel Analog-Digital Conversion System for D-C Voltages

A High-Speed Multichannel AnalogDigital Converter

A Shaft-to-Digital Encoder

Real-Time Digital Differential Analyzer ("Dart")

Session IV-Friday, February 12, 2:00 PM

Data Processing-Equipment

The IBM Magnetic Drum Calculator Type 650-Engineering and Design Considerations

Remington Rand Speed Tally-Design Features

Production Control with the Elecom 125 -Electronic Business System
Richard G. Canning, University of California at Los Angeles, Chairman

Oliver Whitby, Stanford Research Institute

Samuel J. Shaffer, The May Company, Los Angeles

RAYMOND Davis, Librascope, Inc., Glendale, California

HARRY D. HUSKEy, Institute for Numerical Analysis

Myron J. Mendelson, Computer Research Corporation

Roger Sisson, Computer Research Corporation, Hawthorne, California, Chairman

A. K. Susskind, Servomechanism Laboratory, Massachusetts Institute of Technology

W. S. Shockency, Hughes Research and Development Laboratories

James M. Mitchell, J. B. Rea Company, Inc.

B. M. Gordon, M. A. Meyer, R. N. Nicola, Laboratory for Electronics, Inc., Boston, Massachusetts

Loren P. Meissner, U. S. Naval Ordnance Laboratory, Corona, California

Harry E. Burke, Jr., Consolidated Engineering Corporation, Pasadena, California, Chairman

E. S. Hughes, Jr., Endicott Laboratory International Business Machines Corp., Endicott, New York

J. L. HILL, Engineering Research Associates, St. Paul, Minnesota

NoRman Grieser, Underwood Corporation, Long Island City, New York 
A Centralized Data Processing Center

A Merchandise Control System
J. J. Dover, Air Force Flight Test Center, Edwards Air Force Base, Edwards, California

William L. Martin, Telecomputing Corporation, Burbank, California

Discussion groups Friday morning, February 12, included the following topics:

Unit Control in Retail Operations

Numerical Control of Petroleum and Chemical Processes

Numerical Control of Machine Tools

Maintenance Requirements for Business Computers

Mathematical Methods in Management Programming

Symposium on Automatic Programming for Digital Computers. Sponsored by the Navy Mathematical Computing Advisory Panel, a symposium was held in Washington, D. C. on Thursday and Friday, May 13 and 14, 1954.

May 13, Morning Session: C. V. L. Smith, ONR, Washington, Chairman

Definitions, Grace Hopper, Remington Rand Inc., Philadelphia

Differentiators, Harry Kahrimanian, Naval Aviation Supply Office, Philadelphia

Compiler Method of Automatic Programming, NorA Moser, Army Map Service, Washington

Editing Generators, John WaITE, RCA Victor, Camden

New York University Compiler System, Roy GoldFINGER, NYU

Application of Automatic Coding to Logical Processes, Betry Holberton, David Taylor Model Basin

Discussion

May 13, Afternoon Session: Albert E. Smith, BuShips, Washington, Chairman

The MIT Systems: Comprehensive, Summer Session, and Algebraic, C. W. Adams and J. H. LANING, JR., MIT

Interpretive Routines in the Illiac Library, DavId E. MULLER, Univ. of Ill.

Planning Universal Semi-Automatic Coding, SAUL GorN, Ballistics Research Lab., Aberdeen Proving Ground

Present Status of the Michigan Automatic General Integrated Computation (MAGIC), J. H. Brown and J. W. CARR III, Univ. of Mich.

Discussion

May 14, Morning Session: S. B. Williams, Consulting Electrical Engineer, Washington, Chairman

Automatic Programming on the Burroughs Computer, Hubert M. Livingston, Burroughs Corporation

IBM 701 Speed Coding System, John W. Backus and Hardan Herrick, International Business Machines Inc., New York

Programming for the IBM 701 with Repetitively Used Functions, ALlEN KeLler and R. A. Butterworth, General Electric Company, Lynn, Mass.

Discussion

Summary and Forecast, GRACE HopPER, Remington Rand Inc.

National Applied Mathematics Laboratories. The National Bureau of Standards Institute for Numerical Analysis, operated on the Los Angeles Campus of the University of California since 1947, ceased to exist on June 30,1954. Most of its activities will be continued under the sponsorship of the Office of Naval Research and the Office of Ordnance Research under the administration of the Department of Mathematics of the University of California at Los Angeles of which M. R. Hestenes is chairman; C. B. Tomprins will be the Director of the new unit which will be called Numerical Analysis Research, [NAR]. The physical facilities of INA, including the SWAC and the library, will be loaned by the National Bureau of Standards to the University of California. 
A new section, Numerical Analysis, has been established July 1, 1954 by the National Bureau of Standards in Washington; at the same time, the Machine Development Laboratory has been replaced by a section Mathematical Physics. follows:

The new organization of the National Applied Mathematics Laboratories will be as

F. L. Alt, Acting Chief, E. W. Cannon, Assistant Chief

1. Numerical Analysis, J. Tod, Chief

2. Computation Laboratory, M. Abramowitz, Acting Chief

3. Statistical Engineering Laboratory, C. EISEnhart, Chief

4. Mathematical Physics, E. W. Cannon, Chief

\section{OTHER AIDS TO COMPUTATION}

\section{BIBLIOGRAPHY $Z$}

1139. R. R. Bennetr, "Analog computing applied to noise studies," I. R. E., Proc., v. 41, 1953, p. 1509-1513.

A problem of great importance in modern communication engineering is the analysis of noise in linear and nonlinear systems. For a linear system the weighting function (impulsive response, Green's function) completely characterizes the system and is a necessary tool in spectrum shaping analysis. The author discusses the analog simulation of the weighting function using the concept of the adjoint system (cf. H. H. LANNING, JR. \& R. H. Battin, $M T A C$, v. 7, 1953, p. 125). For nonlinear systems the author briefly describes how the amplitude distribution may be shaped using a function generator. Finally, statistical methods-using the concept of confidence levels-are discussed for determining the accuracy, say of the standard deviation, of a number of identical runs on the same physical system.

New York University

K. S. Miller

New York, N. Y.

1140. M. B. Coyle, "An airflow analogy for the solution of transient heat conduction problem," British Jn. Applied Physics, v. 2, 1951, p. 12-17.

The airflow analogy parallels closely the familiar electrical resistancecapacity analogy for transient heat conduction phenomena. Quantity of heat and temperature in the heat conduction system are represented in the airflow system by mass of air and pressure respectively. The continuous thermal system is considered replaced by a lumped system which is simulated by a network of air reservoirs, each containing a mass of air which is a function of the air pressure within it, inter-connected by capillary tubes through which the mass airflow is proportional to the pressure difference between the ends. The air reservoirs are in the form of U-tubes with a confining fluid, all the U-tubes having one leg in common. With this arrangement, the capacity (taken in the electrical sense to mean the mass of air discharged for unit fall in pressure) of a reservoir may be made a function of pressure by constructing it with variable cross-sectional area. Therefore, a problem involving variable thermal properties may be set up with appropriately 